\title{
Existe na Agricultura Brasileira Um Setor que Corresponde ao "Family Farming" Americano?
}

\author{
Carlos Enrique Guanziroli e Alberto Di Sabbato²
}

Resumo: Neste artigo procura-se mostrar a heterogeneidade da agricultura brasileira, que está composta por um segmento altamente produtivo e eficiente, de tipo patronal empresarial; um segmento também eficiente e rentável, de tipo familiar empresarial; e um segmento de agricultores familiares pobres ou camponeses que produz para autoconsumo, mora no estabelecimento, gera emprego para os filhos, e que não migra porque seu custo de oportunidade para migrar é baixo. A inexistência de economias de escala na agricultura, a baixa lucratividade da atividade em função da baixa rotatividade do capital fixo, o ambiente concorrencial do mercado agrícola e os riscos que atingem a atividade (clima, pragas e preços) fazem com que não haja interesse em monopolizá-lo por um setor único de produtores, o que abre espaço, portanto, para a coexistência entre setores heterogêneos do meio rural, cada um com sua própria lógica e seus próprios interesses e reivindicações.

Palavras-chaves: Agricultura familiar, heterogeneidade, resiliência.

Abstract: This article aims to show the diversity of Brazilian agriculture, which is composed by a highly productive and efficient segment made of corporations, a segment also efficient and profitable, entrepreneurial family, and a segment of poor family farmers or peasants who produce for consumption, lives in the establishment, generates jobs for the children, and that does not migrate because its opportunity cost to migrate is low. The absence of economies of scale in agriculture, the low profitability of activity according to the low turnover of fixed capital, the competitive environment of the agricultural market and the risks affecting the activity (climate, pests and rates), do not cause interest in dominating it by a single sector producers, and this makes room for peaceful coexistence between heterogeneous rural sectors, each with its own logic and its own interests and demands.

Key-words: family farming, heterogeneity, resilience.

Classificação JEL: Q100.

1. Professor Associado IV. Faculdade de Economia. Universidade Federal Fluminense (UFF). E-mail: carlos.guanzi@gmail.com

2. Professor Associado IV. Faculdade de Economia. Universidade Federal Fluminense (UFF). E-mail: alberto@economia.uff.br 


\section{Introdução}

Desde 1995, quando foi lançado o programa de fortalecimento da agricultura familiar, pouco se tem avançado em termos teóricos visando enriquecer o debate e implementar soluções criativas.

Do ponto de vista teórico, a maior novidade, após o início da discussão sobre agricultura familiar, foi a introdução do conceito das rendas e/ ou atividades não agrícolas, cuja discussão teve também consequências práticas em termos de redirecionamento de certas políticas agrícolas. Conjuntamente com essa discussão surgiu o debate acerca dos territórios como forma de promover mais eficientemente o desenvolvimento rural.

Na análise empírica sobre o tema da agricultura familiar, a maior parte dos trabalhos apresentados na Sober e posteriormente publicados diz respeito à regionalização do programa (quais regiões são mais ou menos beneficiadas). Outros trabalhos tentaram, sem maior sucesso, efetuar avaliações da eficácia e eficiência do Pronaf em promover aumentos de renda e bem-estar social no campo. A evolução da agricultura familiar através do tempo foi avaliada com a ajuda dos Censos Agropecuários e com aplicação da metodologia que originalmente fundamentou o programa (conhecida como metodologia $\mathrm{FAO} /$ Incra).

Na esfera das políticas houve algumas alterações em relação à proposta original do programa, que resultaram basicamente na incorporação do mesmo à legislação do País (Lei n. 11.326/2006) e na inclusão da questão da comercialização no programa, por meio dos subprogramas PAA (Programa de Abastecimento Alimentar), PNAE (Programa Nacional de Alimentação Escolar) e Programa Mais Alimentos.

A falta de aprofundamento teórico do tema da agricultura familiar deu lugar, no entanto, ao surgimento de fortes questionamentos advindos de setores acadêmicos como a Fundação Getúlio Vargas (FGV) e, mais recentemente, com o lançamento do artigo conhecido como "as sete teses" (BUAINAIN et al., 2013), que glorifica o agronegócio e a grande propriedade como sendo a única alternativa eficiente para o desenvolvimento rural no Brasil.

No sentido contrário, surgiram outras sete teses, "as sete teses camponesas" (VAN DER PLOEG, 2009) que apontam para o outro extremo, fazendo apologia de uma categoria que, a nosso ver, praticamente não existe mais no Brasil contemporâneo: a dos camponeses.

O debate polarizou-se entre os defensores da grande propriedade e os defensores do campesinato, o que fez retroagir a discussão ao nível em que estava na década de 1980, prévio ao rico debate surgido com o advento da categoria da agricultura familiar.

O objetivo deste artigo é tentar recolocar o debate nos eixos que estava antes da recente 
polarização e, para isso, dever-se-á resgatar algumas das questões que estão subjacentes ao tema e que, aparentemente, são desconhecidas tanto por um lado como pelo outro.

O artigo busca, no primeiro capítulo, mostrar que, além do setor de agricultores patronais eficientes, existe outro, de tipo familiar empresarial, capaz de competir no seio do agronegócio. Nos capítulos que seguem são discutidos temas clássicos da temática ligada à agricultura familiar, tais como heterogeneidade e resiliência, que estão ligados indissoluvelmente ao tema de economias de escala, estrutura e dinâmica do mercado agrícola e rentabilidade/risco na agricultura. Finalmente, após discutir a tese da recampesinização, propõe-se uma segmentação nova da agricultura brasileira com políticas agrárias e agrícolas adequadas para cada tipo de público-alvo.

\section{Qual é a real importância da agricultura familiar no Brasil?}

Duas posições antagônicas têm sido difundidas em torno da real importância da agricultura familiar no Brasil: a) a versão oficial, que exagera sua importância e b) a versão das "sete teses" que anula totalmente sua significância em termos produtivos e sociais. Como será demonstrado a seguir, nenhuma das duas corresponde à realidade evidenciada pelos dados do IBGE através dos Censos Agropecuários.

A propaganda oficial vem difundindo repetidamente que a agricultura familiar produz 70\% dos alimentos que o brasileiro consome. Este número é falso e precisa ser desmentido. Vejamos por quê: a agricultura familiar produz uma parte do total produzido de diferentes tipos de alimentos, todos importantes para a dieta do brasileiro, mas cujos percentuais variam bastante, conforme se pode apreciar na Tabela 1 .

Nesta tabela pode-se verificar que existem de fato alguns produtos em relação aos quais a participação da agricultura familiar é bastante relevante e próxima, ou até superior, aos $70 \%$ anunciados pelo governo. Os produtos que aparecem na Tabela 1 com percentuais altos são: leite, cebola, feijão, fumo, mandioca e banana. Mas outros produtos, que também são consumidos pelos brasileiros de forma abundante e permanente, têm baixa participação da agricultura familiar, ou seja, são produtos produzidos predo-

Tabela 1. Participação percentual do valor de produção da agricultura familiar - Brasil - 1996-2006

\begin{tabular}{lcc}
\hline \multicolumn{1}{c}{ Tipo de produção } & $\mathbf{1 9 9 6}$ & $\mathbf{2 0 0 6}$ \\
\hline Pecuária de corte & 23,64 & 16,65 \\
Pecuária de leite & 52,05 & 60,53 \\
Suínos & 58,46 & 52,45 \\
Aves & 39,86 & 30,34 \\
Arroz & 30,87 & 39,19 \\
Cana-de-açúcar & 9,55 & 10,24 \\
Cebola & 72,37 & 69,59 \\
Feijão & 67,23 & 76,57 \\
Fumo & 97,18 & 95,67 \\
Mandioca & 83,88 & 93,17 \\
Milho & 48,57 & 51,90 \\
Soja & 31,62 & 23,60 \\
Trigo & 46,04 & 36,38 \\
Banana & 57,58 & 62,40 \\
Café & 25,47 & 29,67 \\
Laranja & 26,96 & 25,25 \\
Uva & 47,02 & 53,63 \\
\hline Fonte: Guanziroli, Buainain e Di Sabbato (2012).* & \\
* A metodologia seguida pelos autores para o cálculo dos dados é a Metodologia FAO/Incra, \\
cujos detalhes figuram no texto citado.
\end{tabular}


Tabela 2. Evolução da participação das principais variáveis da agricultura familiar - Brasil - 1996-2006

\begin{tabular}{lcc}
\multicolumn{1}{c}{ Variável } & $\mathbf{1 9 9 6}$ & $\mathbf{2 0 0 6}$ \\
\hline \% de estabelecimentos familiares & 85,17 & 87,95 \\
$\%$ da área dos estabelecimentos familiares & 30,48 & 32,00 \\
\% de VBP dos estabelecimentos familiares & 37,91 & 36,11 \\
\% do pessoal ocupado total dos estabelecimentos familiares & 76,85 & 78,75 \\
\hline
\end{tabular}

Fonte: Guanziroli, Buainain e Di Sabbato (2012).

minantemente pela agricultura patronal. Entram nessa lista produtos tais como: carnes (bovina e de aves), soja, trigo, laranja e cana-de-açúcar.

O argumento divulgado pelo governo é inverídico porque induz a suposição de que o brasileiro só consome feijão, mandioca, leite e mais algumas frutas (banana). Mas na verdade, na dieta do brasileiro, entram normalmente outros produtos tais como açúcar, carnes, e outras frutas (que vêm da agricultura patronal) que são consumidas em proporções crescentes à medida que aumenta a renda.

A verdadeira participação da agricultura familiar na produção de alimentos é de $36,11 \%$ como mostra a Tabela 2.

Como afirma o artigo citado (GUANZIROLI, BUAINAIN e DI SABBATO, 2012), essa participação na produção total e, principalmente, a manutenção do mesmo nível de participação durante a década de 1996 a 2006, revela a importância e a força da agricultura familiar, que conseguiu se manter num alto patamar na década de maior desenvolvimento do agronegócio no Brasil. Isso demonstra, portanto, que a agricultura familiar faz parte do agronegócio, já que segue a mesma tendência produtiva e em boa parte dos produtos que produz está inserida nas cadeias agroindustriais típicas do agronegócio moderno (milho, soja, arroz, leite etc.).

Os opositores à agricultura familiar ${ }^{3}$ (ALVES, ROCHA, 2010) são céticos quanto à sua importância e ignoram completamente sua existência. Segundo essa fonte, 30 mil estabelecimentos

3. Cita-se Alves e Rocha (2010) porque as sete teses repetem os argumentos desse trabalho. rurais $(0,62 \%$ do total) foram responsáveis pela metade do valor da produção total e 2,3 milhões seriam responsáveis por magros 3,3\% da renda bruta (sic). Esses agricultores estariam segundo essa fonte, tornando-se "redundantes", tanto os de tamanho médio como os pequenos.

Na verdade, esta tese não tem nada de novo, repete simplesmente a velha tese marxista-leninista da "inviabilidade da pequena produção no regime capitalista de produção", como se nada tivesse sido escrito no último século demonstrando teórica e empiricamente a "resiliência" do agricultor familiar, ou seja, sua relutância a desaparecer e também sobre a grande heterogeneidade que caracteriza o setor rural dos países capitalistas modernos, que permite a coexistência de diferentes formas de produção.

Mas antes de entrar no debate teórico da questão, vejamos novamente o que mostram os dados dos Censos Agropecuários.

Visando mostrar a heterogeneidade existente no seio da agricultura familiar, Guanziroli, Buainain e Di Sabbato (2012) fizeram uma desagregação desta categoria, usando, para esta finalidade, o critério de comparação da renda total anual dos agricultores familiares com o valor do custo de oportunidade ${ }^{4}$.

4. Valor do custo de oportunidade $=\mathrm{V}$, que é o valor de uma diária regional de trabalho agrícola multiplicada por 260 dias e acrescida de $20 \%$, em função de defasagens que existem entre os dados das diárias e dos Censos. Grupo A, com renda total anual superior a $3 \mathrm{~V}$; Grupo B, com renda total anual entre $2 \mathrm{~V}$ e $3 \mathrm{~V}$; Grupo C, com renda total anual entre $1 \mathrm{~V}$ e $2 \mathrm{~V}$; e Grupo D, com renda total anual entre $1 / 2$ $\mathrm{V}$ e $1 \mathrm{~V}$. Para maiores detalhes sobre a metodologia adotada, ver Guanziroli, Buainain e Di Sabbato (2012). 
Tabela 3. Número de agricultores familiares segundo os tipos - Brasil - 1996-2006

\begin{tabular}{ccc}
\hline Tipos familiares & $\mathbf{1 9 9 6}$ & $\mathbf{2 0 0 6}$ \\
\hline A & 406.291 & 452.750 \\
B & 993.751 & 964.140 \\
C & 823.547 & 574.961 \\
D & 1.915 .780 & 2.560 .274 \\
Total & 4.139 .369 & 4.551 .855 \\
\hline
\end{tabular}

Fonte: Tabela extraída de Guanziroli, Buainain e Di Sabbato (2012).

Pela Tabela 3, percebe-se claramente que existe um grupo forte dentro da agricultura familiar, composto por pouco mais de 400 mil produtores gerando uma renda total anual superior a três vezes o valor do custo de oportunidade, mas que existem outros grupos de menor renda total anual que têm aumentado sua importância relativa, principalmente o grupo $\mathrm{D}$, que abrange os mais pobres da agricultura familiar, e que alguns chamam de camponeses ou periféricos.

A Tabela 4 que segue mostra a participação efetiva de cada grupo em relação ao total produzido.
Os dados acima mostram um grande crescimento da participação na produção do grupo A, que passou, nesses dez anos, de $50,6 \%$ para $69,5 \%$ do total.

Os grupos B e C caíram em termos percentuais e o grupo D manteve-se estabilizado em valor de produção, principalmente pelo aumento numérico que teve nesse período.

As mudanças nos valores produzidos ocasionam obviamente alterações na renda média obtida pelos estabelecimentos de cada grupo, como pode ser observado na Tabela 5.

Tabela 4. Participação no Valor Bruto da Produção (VBP) por tipo de renda da agricultura familiar Brasil - 1996-2006

\begin{tabular}{ccc}
\hline \multirow{2}{*}{ Tipos familiares } & \multicolumn{2}{c}{$\%$ s/ Total VBP familiares } \\
\cline { 2 - 3 } & 1996 & 2006 \\
\hline A & 50,6 & 69,5 \\
B & 29,3 & 15,7 \\
C & 9,4 & 4,7 \\
D & 10,7 & 10,1 \\
Total & 100,0 & 100,0 \\
\hline
\end{tabular}

Fonte: Guanziroli, Buainain e Di Sabbato (2012).

Tabela 5. Renda Monetária Líquida Anual por Tipo de Agricultor - Brasil - 1996-2006

\begin{tabular}{ccc}
\hline \multirow{2}{*}{ Tipos } & \multicolumn{2}{c}{ Renda Monetária Líquida Anual* } \\
\cline { 2 - 3 } & 1996 & 2006 \\
\hline Familiares Tipo A & $30.333,00$ & $53.236,00$ \\
Familiares Tipo B & $5.537,00$ & $3.725,00$ \\
Familiares Tipo C & $1.820,00$ & $1.499,00$ \\
Familiares Tipo D & $-265,14$ & 255,00 \\
Patronais & & $70.903,00$ \\
\hline
\end{tabular}

* Descontados os custos de produção, mas não descontada a depreciação.

Valores de 1996 atualizados para 2006 pelo IGP-DI.

Fonte: Tabela extraída de Guanziroli, Buainain, Di Sabbato, 2012. 
Quadro 1. Perfil da agricultura familiar eficiente no Brasil (tipo A) - 2006

\begin{tabular}{|c|c|}
\hline Número Total & $\begin{array}{c}452.700 \text { agricultores } \\
(8,70 \% \text { do total })\end{array}$ \\
\hline Participação no Valor da Produção Total Agrícola do Brasil & $25,1 \%$ \\
\hline Renda Monetária Líquida Anual (valores de 2006) & $\mathrm{R} \$ 53.326$ \\
\hline Área Média por estabelecimento & 48 hectares \\
\hline Especialização na produção (participação superior a $65 \%$ do produto principal) & $72 \%$ são especializados \\
\hline
\end{tabular}

Fonte: Elaboração própria com base em dados recalculados de Guanziroli, Buainain e Di Sabbato (2012).

Fica bem evidente na Tabela 5 que a gradiente de renda entre os grupos é grande e, além disso, aumentou entre 1996 e 2006. O grupo A, que está composto por aproximadamente 450 mil produtores, gerou, em 2006, renda média anual líquida bastante elevada, que equivalia a quase $\mathrm{R} \$ 4.500$ por mês de ganho monetário. Ao se considerar que nas áreas rurais os produtores têm acesso a outras rendas não agrícolas, a quase-rendas (como o autoconsumo) e que não pagam aluguel, o valor equivale a um padrão de vida de classe média urbana. Este grupo é o mais semelhante ao "familiy farm" americano que existe na agricultura brasileira.

Este segmento composto por 400 mil agricultores aproximadamente pode ser caracterizado da seguinte forma.

Está assim caracterizado o perfil da agricultura familiar efetivamente produtiva no Brasil, que de alguma forma se assemelha ao "family farm" americano, French paysans ou landwirtschaftlicher Familienbetriebe de Alemanha. Trata-se, como pode se observar acima, de um grupo especializado, que gera renda líquida suficiente para consumir comprando seus produtos no mercado e também para investir em novas tecnologias e atividades e que possui uma área média razoável ${ }^{5}$.

Cabe assinalar que este segmento da agricultura do Brasil é de tipo familiar: ou seja, desenvolve suas atividades com mais trabalho familiar que contratado (UTF>UTC, segundo a metodo-

5. Cabe assinalar que se trata de uma média, e por esse motivo inclui valores que oscilam desde rendas líquidas de mais de $R \$ 250.000$ por ano e áreas com aproximadamente 250 hectares em algumas regiões, até valores mais baixos. Mas sem perder o atributo de serem familiares, ou seja, de ter mão de obra familiar superior à contratada. logia FAO/Incra) (ver GUANZIROLI, BUAINAIN e DI SABBATO, 2012).

Mas as tabelas anteriores mostram também que outros segmentos dentre os agricultores familiares produziam menos em proporção e tinham rendas líquidas menores que as do grupo A. São grupos numerosos que se aproximam dos valores citados por Alves e Rocha (2010), mas que não são tão desprezíveis como eles querem fazer crer. Trata-se de segmentos da agricultura familiar que produzem basicamente para autoconsumo, como os caboclos do sertão nordestino que não têm condições de se integrar positivamente nos mercados, o que não é nenhum demérito em relação à sua condição social, uma vez que, ao invés de migrar para o Sul e contribuir com o inchaço das cidades, penam para sobreviver o mais dignamente possível nas regióes pouco favorecidas onde nasceram. Contribuem também, embora mais modestamente que os outros, com o abastecimento de suas cidades e regiões de origem.

Também nos Estados Unidos existe grande heterogeneidade na composição do seu setor agrícola, como mostra a tabela extraída do UDSA apresentada a seguir.

A Tabela 6 mostra uma realidade bastante parecida com a brasileira: existe nos EEUU um número equivalente a $8,2 \%$ (soma de familiares médios e grandes) do total de agricultores que produzem em torno de $48 \%$ do total produzido na agricultura americana e que controla, por sua vez, quase $30 \%$ dos ativos, incluindo a terra.

A heterogeneidade se manifesta também pela quantidade de outros tipos de produtores, tais como: aposentados, de vendas baixas, de atividades não agrícolas etc., compondo um panorama 
Tabela 6. Distribuição percentual dos estabelecimentos por valor da produção, e ativos nos EEUU 2012

\begin{tabular}{lccc}
\hline \multicolumn{1}{c}{ Tipos } & $\begin{array}{c}\text { Número de Fazendas } \\
(\boldsymbol{\%})\end{array}$ & $\begin{array}{c}\text { Valor da produção } \\
(\boldsymbol{\%})\end{array}$ & $\begin{array}{c}\text { Ativos } \\
\mathbf{( \% )}\end{array}$ \\
\hline Aposentados & 18,1 & 0,8 & 9,5 \\
Ocupação não agrícola & 37,6 & 4,6 & 19,4 \\
Ocupação agrícola: vendas baixas & 27,9 & 6,9 & 20,8 \\
Ocupação agrícola: vendas moderadas & 5,4 & 10,8 & 9,7 \\
Agricultores familiares de tamanho médio & 5,4 & 20,2 & 15,4 \\
Agricultores familiares grandes & 2,6 & 27,8 & 14,0 \\
Agricultores familiares muito grandes & 0,2 & 13,7 & 3,6 \\
Não familiares & 2,8 & 15,2 & 7,5 \\
\hline
\end{tabular}

Fonte: USDA, Economic Research Service and National Agricultural Statistics Service, 2012 Agricultural Resource Management Survey.

de clara convivência entre diferentes formas de produzir, contrariamente ao rígido esquema caracterizado e pré-anunciado no artigo das sete teses. Percebe-se, portanto, que não são apenas os casos de agricultura europeia que estariam inspirando os autores brasileiros (sete teses).

Veiga (1991, p. 6) mostra, nesse sentido, que o

[...] caráter essencialmente familiar da agricultura norte-americana não parou de se afirmar. Ao contrário do que muitos pensam, as 'corporações' são exceção. O último censo agropecuário, de 1992, revela que a participação destas nas vendas do setor é declinante - apenas $6 \%$ (US\$ 9,8 bilhões). As vendas das sociedades de tipo familiar aumentaram, chegando a $21 \%$ (US\$ 34,4 bilhões). Já a tradicional agricultura familiar foi responsável por $54 \%$ da produção comercializada (US\$ 87,9 bilhões). Os restantes 19\% (US\$ 30,5 bilhões) vieram de formas societárias não classificadas como familiares ou patronais. Assim, mesmo a tremenda evolução organizacional da agricultura daquele país ocorrida neste século não alterou de modo significativo seu caráter essencialmente familiar.

A Tabela 7 mostra que em 2007 o percentual da produção controlada pelos agricultores familiares era alto $-50 \%$. O das corporações ficou estável. Outros dados extraídos de USDA revelam que, no caso do milho, 67\% são produzidos por agricultores familiares, do trigo, $60 \%$ e da soja, $65 \%$ - acima da média também são produzidos por agricultores familiares. Os agricultores americanos com até um operador empregado controlam $45 \%$ das vendas e $52 \%$ da terra e trabalham em áreas de apenas 379 hectares em média, ou seja, são tipicamente familiares (family farm).

A manutenção e em alguns casos o crescimento da importância na agricultura familiar (não da pequena produção) tanto no Brasil como nos EEUU mostra que este segmento insiste em não desaparecer, apesar dos prognósticos pessimistas dos teóricos marxistas e de alguns acadêmicos brasileiros (ALVES, ROCHA, 2010). Os censos agropecuários brasileiros mostram que a cada década que passa o número de agricultores

Tabela 7. Participação Percentual no Total de Vendas de Produtos Agropecuários por Tipo de Agricultor Estados Unidos

\begin{tabular}{lcc}
\hline \multirow{1}{*}{ Tipo de agricultor } & \multicolumn{2}{c}{ Percentual Produção Total (\%) } \\
\cline { 2 - 3 } & 1992 & 2007 \\
\hline Agricultores Familiares & 54 & 50 \\
Sociedades familiares & 21 & 22 \\
Sociedades em geral & 19 & 22 \\
Corporações & 6 & 6 \\
Total & 100 & 100 \\
\hline
\end{tabular}

Fonte: USDA. Censos Agropecuários dos Estados Unidos 1999 e 2007. 
familiares se mantém constante e sua participação na produção também. Este fenômeno, por alguns chamado de "resiliência", será mais bem discutido na próxima seção.

\section{O que explica a heterogeneidade da agricultura e a resiliência da agricultura familiar?}

Conforme visto antes, a agricultura familiar não é um segmento insignificante na agricultura brasileira, nem tampouco na norte-americana. Cabe descobrir agora que fatores teriam ajudado historicamente na manutenção deste setor na economia dos países.

\subsection{Não é um resquício do feudalismo, trata-se de um fenômeno do século XX}

Buttel e LaRamee (1991) explicam que o fenômeno da agricultura familiar não é um resquício de formas arcaicas ou feudais de produção. Isso seria característico da agricultura camponesa, como se verá mais adiante. A agricultura familiar seria uma forma de produzir nova, que cresceu e se desenvolveu principalmente no século $X X$, em função de vários tipos de políticas agrícolas e agrárias seguidas principalmente pelos países desenvolvidos. Cabe citar entre esses apoios os que as Farms Bills estadunidenses (leis agrícolas de Roosevelt que começaram nos anos 30 e que se seguiram aplicando até o presente) e a CAP (Common Agricultural Policy) da União Europeia, deram aos seus agricultores na forma de preços mínimos, tarifas e subsídios à produção. O presidente J. F. Kennedy deu novo apoio aos agricultores familiares, promovendo inclusive políticas de reforma agrária na América Latina. Na Europa, esta política, aplicada entre os anos 1950 e o presente, permitiu que se recuperasse e fortalecesse o outrora decaído segmento agrícola europeu.

Outros países agiram de forma semelhante, tanto no que diz respeito à reestruturação dos seus setores agrários (Japão, Taiwan, Coreia do Sul, Chile) como no que se refere aos meca- nismos de sustentação de suas agriculturas. Paradoxalmente, foram políticos de direita ou centro-direita os que aplicaram essas políticas.

Os únicos países que não apoiaram seus pequenos fazendeiros foram os países socialistas, que optaram por um modo de produção de grandes fazendas estatais que fracassou totalmente e que teve que ser revertido a formas menores de produção após o fim do sistema socialista e/ou de suas reformas recentes (caso de China).

A existência e persistência de formas de produzir baseadas na pequena produção em quase todos os países capitalistas e os apoios dados de forma sistemática a essa forma de produzir em todos esses países capitalistas revela que sua lógica coaduna-se com a lógica econômica do sistema capitalista. Se fosse um setor inútil ou ineficiente, que razão lógica justificaria alocar enormes quantias de recursos nesse setor?

\subsection{Baixa rentabilidade e alto risco na agricultura abrem espaço para a convivência entre formas de produção diferentes}

Para encontrar argumentos lógicos que expliquem a resiliência da agricultura familiar deve-se recorrer a autores clássicos que em algum momento da história recente estabeleceram princípios paradigmáticos nessa discussão sem terem sido refutados até o presente momento.

Mann e Dickinson (1978) mostram que a lógica da agricultura familiar se insere no que denominam "especificidade do setor agrícola". Na agricultura, diferente da indústria, a natureza age de diferentes maneiras, ocasionando principalmente uma ruptura no ciclo produtivo, que tem que esperar a ação da natureza para prosseguir na elaboração do produto final. Ou seja, durante certa quantidade de tempo a aplicação de trabalho ao processo de produção se interrompe, seja porque as plantas estão simplesmente crescendo e para isso dependem da natureza e do seu ciclo germinativo, ou porque os animais estão sendo gestados ou amadurecendo, e nesse tempo o trabalho humano não pode colaborar. Sendo assim, 
existem momentos importantes nos quais tanto o trabalho como o capital fixo ficam em estado letárgico à espera da natureza, mas incidindo com custos na contabilidade empresarial. Estes momentos sobrecarregam o denominador da equação de taxa de lucro, sem acrescentar nada no numerador (taxa de lucro $=$ valor da produção/custos fixos + custos variáveis).

Isto gera baixa rentabilidade em cada ciclo produtivo, que é agravada também pelo fato de que o numerador se reduz a um ciclo só de produção (ou seja, não se repete, como acontece na indústria), ocasionando "baixa rotação do capital fixo" e, portanto baixa lucratividade. Além disso, na agricultura (cereais, principalmente) devem-se manter estoques para contrapor os baixos preços da fase da colheita (o que tem custo), e quando são perecíveis (hortigranjeiros e frutas) a não venda no momento certo ocasiona grandes prejuízos que diminuem sua rentabilidade.

Somados a estes problemas, na agricultura, diferente da indústria, a atividade produtiva enfrenta três tipos de risco diferentes, que muitas vezes se superpõem, gerando situações catastróficas. São os riscos de Clima, Pragas e Preços.

Nenhuma atividade industrial sofre de problemas tais como falta de chuva, enchente, seca, pragas de insetos, fungos ou ervas daninhas, nem seus preços oscilam tanto como oscilam na agricultura. $\mathrm{Na}$ indústria, de fato, os preços são relativamente estáveis dependendo basicamente do mark up estabelecido entre os oligopólios e menos da demanda efetiva por seus produtos. $\mathrm{Na}$ agricultura, os preços dependem basicamente das oscilações de estoques, do clima, da demanda e de outros fatores como a especulação, que agem nas bolsas de mercadorias e futuros.

Todos estes fatores (baixa taxa de lucro, baixa rotação do capital fixo, custo de manutenção de estoques, perecibilidade, riscos de clima, pragas e preços) geram pouca atratividade para que os setores capitalistas invistam na agricultura, deixando espaço, portanto, para a convivência com outras formas de produzir (familiares e camponesas) que não têm custo de oportunidade tão alto como os capitalistas para investir na agricul- tura: para ficarem no campo basta obter uma taxa de lucro mínima que garanta a sobrevivência da família. Neste sentido, é comum dizer que o agricultor familiar maximiza renda familiar, enquanto o capitalista maximiza taxa de lucro.

Este raciocínio não implica dizer que os capitalistas não investem na agricultura. Eles investem sempre que haja proteção para enfrentar riscos, em termos de subsídios, juros, créditos, tarifas e tolerância com os defaults. Mas mesmo assim não conseguem ocupar produtivamente todos os espaços e territórios rurais de um país do tamanho do Brasil.

Do total de 850 milhões de hectares que o Brasil possui de superfície, apenas 56 milhões estão plantados com cereais ou lavouras permanentes, ou seja, menos de $10 \%$ da sua área total. Outros 155 milhões de hectares estão ocupados com pastagens, das quais somente 92 milhões são pastagens plantadas em boas condições. $\mathrm{O}$ restante são pastagens naturais, áreas sem uso algum, matas, florestas, lagoas, lagos, cidades etc. (IBGE, 2006).

Deixando de lado todas as regiões e áreas que sofrem de restrições ambientais, sobrariam pelo menos uns 150 milhões de hectares para aumento/expansão da produção agropecuária no Brasil.

Percebe-se, portanto, que o dinamismo do agronegócio no Brasil não foi até agora suficientemente forte para ocupar todas as áreas rurais do país.

Nesse processo abrem-se janelas de oportunidade e espaço para que outros agricultores, como os familiares, se desenvolvam e ganhem expressão.

\subsection{Estrutura de mercado concorrencial na agricultura garante heterogeneidade}

Nessa mesma linha, mas seguindo um raciocínio "ricardiano", Vergopoulos (1978) mostra que o agricultor familiar não se considera a si mesmo como um capitalista que deve maximizar uma taxa de lucro, mas se considera um trabalhador que deve garantir sua sobrevivência e nada mais. 
Ele não contabiliza lucro, nem renda da terra e remunera o trabalho familiar ao seu custo de oportunidade ao invés de considerar a produtividade marginal do mesmo (p. 446). Desta forma consegue entregar os produtos no mercado pelo preço mais baixo possível (sem lucro, nem salário) o que gera evidentes benefícios ao sistema capitalista industrial que calcula o salário industrial em função do custo dos alimentos (efeito ricardiano) e os lucros como a quantia que sobra da receita total depois de restar os salários e os outros custos de produção.

Esta dinâmica de geração de rendas e lucros está determinada, na agricultura, por uma estrutura de mercado muito peculiar nos tempos modernos. A agricultura, ao contrário da indústria, na sua fase exclusivamente campestre (dentro das porteiras) é uma atividade regida por concorrência quase perfeita.

Trata-se de um setor que produz produtos homogêneos, que está totalmente atomizado num sem-número de produtores, que não exercem nenhum poder na determinação do preço final dos produtos. Ou seja, não existe a menor possibilidade de um produtor, seja ele grande e moderno ou tradicional, de poder determinar o preço de seu produto em condições diferenciadas em relação ao de outro agricultor. A agricultura não se caracteriza por ter um grupo pequeno de produtores controlando a oferta: existem $250 \mathrm{mil}$ produtores de soja, mais de 1 milhão de produtores de feijão, 2 milhões de produtores de milho, etc., enquanto na indústria automobilística, por exemplo, não há mais que uma dúzia de empresas determinando preços de forma oligopolística.

Fora das porteiras, nos setores a jusante e a montante do setor agrícola, predominam estruturas clássicas de tipo oligopólico, mas não na agricultura propriamente dita, o que impede que um setor de agricultores se beneficie por suas características produtivas em relação a outros produtores. Por este motivo, na agricultura funcionam bem as bolsas de mercadorias, o que não acontece em nenhum setor industrial. Quem fixa preço na agricultura são as bolsas, seja a de Chicago, Londres, Amsterdam ou Singapura e não um grupo restrito de produtores como é na indústria. Os agricultores são "price takers".

Esta particularidade da agricultura em relação à indústria aumenta mais as possibilidades de convivência e a heterogeneidade deste setor, que não exclui ninguém em termos de qualidade e preço dos seus produtos. Excetuando produtos muito processados (queijos especiais, embutidos etc.) a maior parte dos produtos são commodities homogêneas.

Na verdade, a existência de um mercado de concorrência quase perfeita (spot market) acaba sendo bastante arriscada para o produtor, que vê seus preços diminuírem à medida que aumenta a oferta. Esta forma perversa de funcionamento do mercado beneficia invariavelmente o consumidor final, que é o alvo principal do sistema capitalista (bem-estar do consumidor). O agricultor, para compensar a tendência decrescente dos preços, tem que reagir aumentando sua produção permanentemente, via aumentos de produtividade ou de área, ficando preso desta forma à tesoura clássica: custos altos e preços baixos, que é a dinâmica que garantiu historicamente o "squeeze" da agricultura em benefício da indústria.

$\mathrm{O}$ agricultor familiar pode ser retratado como se fosse o operador das antigas rodas de água: pedala, pedala e fica sempre no mesmo lugar, mas não esmorece porque não tem alternativas válidas de ocupação no setor urbano.

Em suma, não há nada de romântico na permanência da agricultura familiar na agricultura moderna: ela cumpre uma função positiva na engrenagem de produção capitalista a qual, perversamente, garante sua sustentabilidade.

\subsection{Inexistência de economias de escala na agricultura impede a exclusão definitiva da pequena produção}

Fica claro no trabalho de Binswanger (1989) e de outros autores (LUND e HILL, 1979; STANTON, 1978; KRAUSE, 1988) que na agricultura, salvo raras exceções, não existem economias de escala. Os grandes e médios proprietários têm algumas vantagens econômicas relacionadas com 
Figura 1. Simulação de Economias de Escala na Agricultura

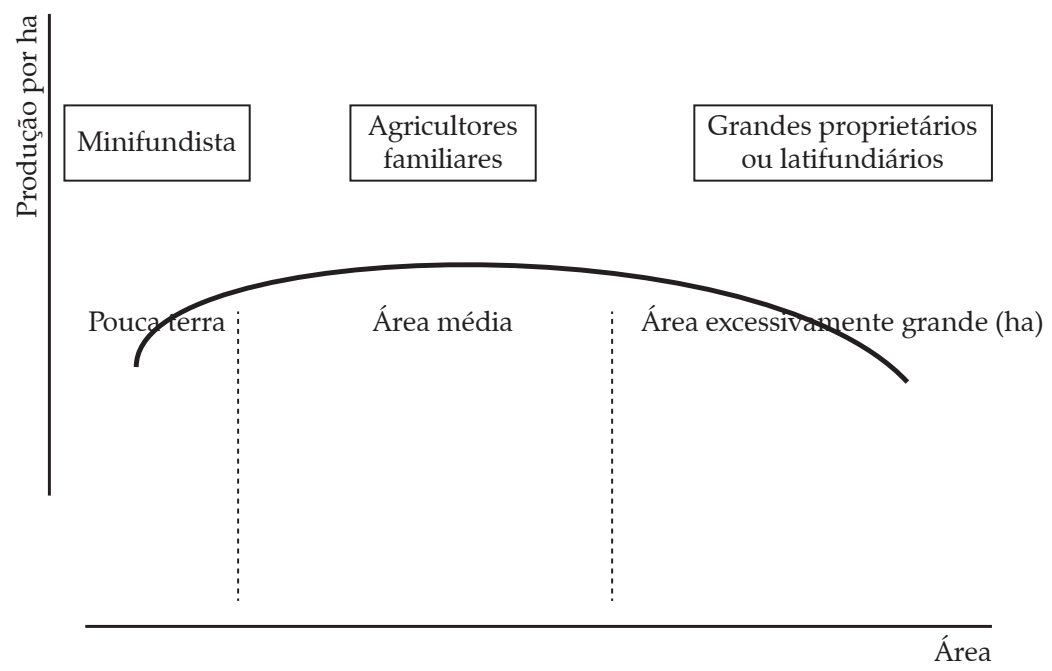

Fonte: Elaboração própria.

a utilização de alguns equipamentos indivisíveis, que não podem ser rentabilizados em pequena escala, e pelas facilidades de crédito e de comercialização. A mecanização, no entanto, pode ser feita também em áreas pequenas, por meio do aluguel de máquinas ou pela compra em grupos comunitários. As grandes empresas agrícolas têm como desvantagem os custos de supervisão e gestão da produção que, na agricultura, diferentemente da indústria, são extremamente altos quando se trabalha em grandes extensões de terra e se contrata um grande número de trabalhadores.

Os agricultores familiares têm vantagens justamente nessa área da gestão do trabalho; os motivos são os seguintes: a) os membros das famílias participam dos lucros e, por isso, têm mais incentivos para trabalhar; b) não há custo de contratação e busca de trabalhadores; e c) ao participar também dos riscos, os membros da família assumem os prejuízos sem necessidade de aumentar os preços dos produtos (BINSWANGER, 1989).

A pouca incidência de economias de escala pode ser representada graficamente como na Figura 1.

Lund e Hill (1979) verificaram que em vários setores da atividade agropecuária os rendimen- tos da terra, como proxis de eficiência, ou a produtividade total dos fatores, têm uma relação semelhante à apresentada na Figura 1 (curva U invertida). No intervalo de 0 até um certo tamanho mínimo (o das unidades muito pequenas), haveria economias de escala, ou seja, à medida que crescem em tamanho melhoram seus rendimentos por área. Uma vez alcançado este limite abre-se um amplo espaço de economias constantes de escala, ou seja, aumenta o tamanho, mas os rendimentos não aumentam proporcionalmente, porque todas as inovações tecnológicas já foram incorporadas ${ }^{6}$. Ao superar um tamanho máximo, as propriedades tornam-se improdutivas porque começam a atuar deseconomias de escala, basicamente os custos crescentes de gestão e supervisão da produção.

$\mathrm{Na}$ área de economias de escala crescentes é onde atuam preferencialmente os pequenos produtores que ainda não se mecanizaram por falta de escala, que comercializam em volumes pequenos, pelo que obtêm preços menores e compram

6. Berry e Cline (1979) encontraram uma curva tipo S, já que os grandes estabelecimentos são os primeiros a introduzir as inovações tecnológicas, seguidos pelos pequenos, o que fixa o nível para as economias de escala em um ponto mais alto da renda dos agricultores. 
insumos em volumes pequenos, pelo que pagam mais que os outros compradores. Os que estão na fase de economias de escala constante são os agricultores familiares, que já incorporam as tecnologias necessárias e que para aumentar a produção basta usarem múltiplos dos insumos anteriormente usados, inclusive na mecanização (insumos neutrais a escala ou divisíveis).

Os agricultores excessivamente grandes enfrentam problemas com a distância que as máquinas têm que percorrer dentro dos estabelecimentos e com a gestão e supervisão da atividade em áreas muito extensas.

As grandes explorações têm, sem dúvida, maior capacidade de rentabilizar os segmentos de suporte, como transporte, processamento, comercialização das mercadorias e inputs, mas estas não são atividades "porteira adentro", ou estritamente de produção agropecuária.

\section{As políticas públicas garantem o funcionamento da agricultura e do agronegócio no Brasil}

Não havendo argumentos econômicos relevantes que expliquem tanto a existência das grandes propriedades como das muito pequenas, sobra apenas o argumento das políticas públicas, como diz Binswanger, em obra citada anteriormente. As políticas públicas, sob o manto de todo tipo de subsídios e facilidades dados aos grandes proprietários, têm efetivamente contribuído para alterar o formato ideal das propriedades e sua forma de gestão na América Latina.

Têm sido os subsídios ao crédito e os incentivos fiscais, aliados aos baixos salários que, ao compensar os riscos da natureza e a baixa rentabilidade natural da agricultura, permitiram a sobrevivência e expansão das unidades patronais extensivas.

Como pode se apreciar na Tabela 8, no último Plano Agrícola e Pecuário (2014/2015) foram definidos valores e condições de crédito para as diferentes modalidades de suporte a agricultura bastante favorecidos.

O valor a ser destinado para estas operações é de 156 bilhões de reais, sendo que, deste valor, apenas 24 bilhões de reais irão para a agricultura familiar.

Mas o que é importante destacar nesta tabela divulgada pelo Ministério de Agricultura, Pecuária e Abastecimento (Mapa) são as taxas de juros a serem cobradas. Como pode se verificar na Tabela 8, nenhuma linha de crédito supera os $7,5 \%$ ao ano de juros, sendo que algumas linhas, como o Moderfrota, cobram menos de $5 \%$ ao ano de juros.

Tabela 8. Taxas de juros anuais do Plano Agrícola e Pecuário 2014/2015 - Brasil

\begin{tabular}{lcc}
\multicolumn{1}{c}{ Finalidades } & \multicolumn{2}{c}{ (\% ano) } \\
\cline { 2 - 3 } & $2013 / 14$ & $2014 / 15$ \\
\hline Custeio e Comercialização & 5,5 & 6,5 \\
Médio Produtor (Pronamp) & 4,5 & 5,5 \\
Funcafe & 5,5 & 6,5 \\
Investimentos & & \\
$\quad$ - Moderfrota (reativar) & 5,5 & 4,5 e 6,0 \\
$\quad$ - Irrigação / Inovação / Armazenagem & 3,5 & 4,0 \\
- Programa ABC & 4,5 e 5,0 & 4,5 e 5,0 \\
- PSI - Rural & 4,5 e 6,0 & 4,5 e 6,0 \\
$\quad$ Cerealistas & 4,5 e 6,0 & 5,0 \\
$\quad$ - Médio Produtor (Pronamp) & 4,5 & 5,5 \\
$\quad$ - Outros investimentos & 5,5 & 6,5 \\
Cooperativas & & \\
$\quad$ - Capital de giro (Procap-Agro) & 6,5 & 7,5 \\
$\quad$ - Investimento & 5,5 & 6,5 \\
Fundos Constitucionais & 3,0 & 5,7 a 7,2 \\
\hline
\end{tabular}

Fonte: Mapa, 2014. 
Considerando que a taxa Selic está hoje (junho 2014) em 11\% ao ano, o Governo está dando um subsídio médio aos produtores (que em sua maior parte são empresários rurais) de aproximadamente $6 \%$ ao ano, que aplicados no valor de $\mathrm{R} \$ 156$ bilhões, dá um total de quase $\mathrm{R} \$$ 10 bilhões que não são recuperados no quesito juros. Se a comparação for feita com a taxa média de juros de crédito ao consumidor, que está na faixa de $35 \%$ ao ano, o subsídio será muito maior.

O agronegócio foi beneficiado no passado e continua contando no presente com outros tipos de apoio, tais como a transferência gratuita de tecnologia feita pela Embrapa, programas de colonização dos Cerrados nos anos 80 a fundo perdido (Prodecer), fundos setoriais, subsídio no Proálcool, subsídio de $50 \%$ no prêmio do seguro rural, etc., sem falar das continuadas prorrogações, anistias, e securitizações de dívidas das quais se beneficiou no passado recente.

Pode-se afirmar, portanto, que além das boas condições do mercado mundial e a capacidade e iniciativa dos empresários rurais brasileiros, o sucesso do agronegócio deve ser, em parte, debitado também aos esforços envidados pelo Governo junto ao setor agropecuário, que garantiu, de todas as formas possíveis, que o setor fosse atendido com crédito a juros baixos e que os riscos fossem compensados com seguros rurais subsidiados e com prorrogações, quando necessário.

\section{Fatores sociológicos e antropológicos que explicam a persistência do campesinato no Brasil}

Existem fatores, de ordem sociológica e/ou antropológica, que permitem entender porque agricultores muito pequenos, que habitam terras improdutivas e que não têm terra suficiente para gerar lucros razoáveis, persistem em não abandonar a área rural onde moram.

Gasson et al. (1988) enumeram alguns desses fatores e explicam sua lógica de forma bastante convincente. Segundo estes autores, os agricultores pobres (que no Brasil estão na faixa dos 3 milhões de estabelecimentos) optam por não abandonar a terra porque usufruem de outras vantagens, que têm também um significado econômico.

O primeiro argumento, e talvez o mais importante, diz respeito à moradia, que eles possuem na terra onde moram, enquanto que, se mudassem para a cidade, teriam que pagar aluguel. Isso faz uma diferença considerável quando se vê que a renda monetária que poderiam ganhar em algum emprego urbano seria muito pequena e incompatível com o pagamento de aluguel.

O segundo argumento trata do autoconsumo. Este tema, que para alguns é sinônimo de atraso, é garantia de sobrevivência para muitos habitantes deste País. Os camponeses pobres que produzem sua comida evitam ter que comprá-la no supermercado. Se eles vendessem sua produção na época da colheita e fossem comprá-la na entressafra perderiam uma boa diferença. Faz muito mais sentido, nessas condições, abastecer-se com o que se produz a preço de custo do que comprar esse mesmo produto no mercado. Por outro lado, se mudassem para a cidade, teriam que dispor de renda suficiente para pagar pelos alimentos, que hoje produzem quase gratuitamente.

$\mathrm{O}$ terceiro argumento diz respeito à geração de emprego para os filhos. $\mathrm{O}$ agricultor familiar pobre, chamado de camponês por alguns, pode gerar emprego para seus filhos e agregados sem maior problema. Obviamente que se trata de subemprego que provavelmente estará na linha de produtividade marginal nula como explica Lewis (1954), e que, portanto não recebe salário. A remuneração estará dada pela repartição da renda total da família, em boa parte na forma de autoconsumo, mas considerando-se que muitos jovens têm baixo custo de oportunidade, sobretudo no semiárido nordestino. Às vezes, este tipo de situação de subemprego apresenta-se como uma alternativa válida em relação à possibilidade de estar desempregado nas cidades, trabalhar em empregos muito precários ou cair na marginalidade.

$\mathrm{O}$ quarto argumento, embora mais novo em termos de pesquisa, é evidente em algumas regi- 
ões do país. Trata-se da possibilidade que alguns camponeses têm de realizar atividades rurais não agrícolas sem abandonar as atividades propriamente agrícolas, ou reduzindo seu esforço nas mesmas, se for conveniente. Em alguns casos, trata-se simplesmente de empregos desqualificados que alguns dos membros da família conseguem realizar, tais como emprego doméstico, diárias eventuais, fretes, etc. Na verdade, estas atividades têm pouca ou nenhuma relação com o fato de se possuir terra na área rural. Mas existem outras que estão imbricadas com a atividade rural e que pressupõem a existência de um estabelecimento rural, por mais pobre que seja, como, por exemplo, artesanato rural, turismo rural e agroindústria rural. Esta oportunidade ajuda a decidir se valeria a pena migrar ou não para uma cidade, já que, da mesma forma que as anteriores, têm uma vantagem econômica evidente. Infelizmente, atividades rurais deste tipo são as menos frequentes no meio rural.

Existem outros motivos que são mais sutis, ou menos evidentes em relação ao seu significado econômico, mas que exercem influência na decisão de não abandonar a área rural.

Gasson et al. (1988) destacam a "sensação de autonomia" que o camponês tem em relação a seu trabalho. Isto, que pode parecer meio romântico, tem certa influência psicológica na hora de tomar uma decisão. $\mathrm{O}$ agricultor sabe que, apesar de pobre, ele decide o que fazer de seu tempo e de sua vida e que se tiver sorte em algum momento pode dar um salto e prosperar, enquanto que, se ele migrar para uma cidade, vai ser um peão de obra, que trabalhará sob as ordens de um patrão ou chefe a vida inteira, com pouca ou nula perspectiva de melhora. Trata-se do sonho da autonomia que todo mundo tem e que ele desfruta atualmente, embora em condições precárias.

Ligado a este motivo, os autores citados ressaltam também outro fator que a sociologia e a antropologia costumam estudar, que se refere à "vida em comunidade". Os agricultores vivem, principalmente no Nordeste, em ambientes comunitários, nos quais têm uma vida social e também apoios mútuos em suas atividades coti- dianas. O "mutirão" é uma ação de tipo comunitário que tem consequências econômicas, como, por exemplo, quando os membros das comunidades se ajudam entre si para construir suas casas, suas cisternas ou para preparar a terra. Embora se trate de troca de horas de trabalho, que ele poderia vender para outros, acaba representando uma ajuda efetiva para as famílias. Numa condição urbana, ele teria que contratar pedreiros para fazer uma casa ou um galpão, enquanto que no campo ele faz sem custo de mão de obra. Juntamente com este fator, os autores citados incluem também o lazer e a satisfação de viver em comunidade como fatores que podem influenciar decisões de mudança.

Finalmente, há um fator da máxima importância, mas que é pouco percebido pelos analistas em geral. Diz respeito ao controle intergeracional da terra. O agricultor, inconscientemente, está sempre fazendo o seguinte cálculo: se imputar todos os custos embutidos das atividades laborais não pagas aos filhos, o resultado de sua atividade rural (agrícola ou não agrícola) será sempre negativo. Mas se, ao mesmo tempo, calcular a valorização de seu patrimônio ao longo do tempo e dividir essa valorização em parcelas anuais, o resultado negativo é compensado, com vantagens. Embora ele não saiba, a terra, por ser um ativo não renovável, é o ativo que mais se valoriza no longo prazo, e se ele conseguir passar esse ativo para os filhos estará realizando o maior sonho de todo homem que é o de se perpetuar através da herança, na vida dos seus descendentes.

Todos estes fatores, somados ou não, exercem uma influência importante na explicação de porque agricultores pobres, camponeses, apesar de estarem na linha de economias de escala crescentes (sem economia de escala), teimam em não abandonar a terra, ou em outras palavras porque são "resilientes".

Resta agora explicar porque os fazendeiros muito grandes, improdutivos ou ociosos, tampouco abandonam as áreas rurais. Além dos argumentos antes expostos (subsídios, tolerância com inadimplências nos créditos e monopólio na contratação de mão de obra) eles usufruem tam- 
bém de outras vantagens psicológicas/antropológicas, que podem ter consequências econômicas, tais como o status e prestígio que é conferido pelo controle de grandes porções de terra. Esse controle redunda em poder político, o que acarreta, por sua vez, poder econômico na gestão de créditos, liberação de recursos, obras de infraestrutura, etc.

A valorização da terra é, também neste caso, um chamariz importante para a compra de terras, muitas vezes improdutivas ou longínquas dos centros urbanos, mas que graças a obras de infraestrutura - que acabam chegando a esses lugares - multiplicam seu valor inicial por várias vezes. Em tempos inflacionários a terra cumpre uma função de hedge ou de reserva de valor em relação a outras atividades de maior risco.

\section{6. É possível "recampesinizar" a agricultura brasileira?}

Uma das questões colaterais que vem sendo discutida nos últimos tempos é a tese de volta ao campesinato, defendida entre outros por Van der Ploeg (2009). Sem entrar nos detalhes dessa tese, nossa visão a esse respeito é que se trata de uma visão sonhadora, inexequível e retrógrada, se for aplicada ao caso brasileiro.

Embora haja muitas dúvidas sobre o papel do agronegócio no Brasil, não há como negar que este setor tomou conta da produção agrícola e que isso aconteceu em função da confluência de vários fatores, tais como adoção de tecnolo- gias modernas, políticas agrícolas adequadas e oportunas e o fim do viés antirrural da política macroeconômica que vigorou durante o processo de substituição de importações. Fica claro também que este desenvolvimento foi apoiado fortemente pelo Estado que removeu alguns entraves estruturais que impediam seu avanço, como a defasagem tecnológica, o acesso à terra no Centro-Oeste, a liberalização comercial, a lei Kandir etc.

Mas hoje é uma realidade que avança inexoravelmente, e que, no máximo, poderá no futuro ser combinada com formas avançadas de agricultura familiar que permitam inserir agricultores médios e pequenos em áreas de forte predomínio do agronegócio (Sudeste e Centro-Oeste) e fortalecer agricultores familiares em outras áreas nas quais há mais liberdade de ação, pelo preço baixo da terra (Nordeste, Norte).

Embora esses setores modernos coexistam com outros setores pobres da agricultura familiar, também chamados de camponeses, que têm sua lógica e papel dentro da enorme heterogeneidade que caracteriza a agricultura brasileira, a volta dos setores modernos para um estágio anterior, ou seja, a recampesinização, seria anacrônico como o Quadro 2 mostrará.

Segundo Friedmann (1980), nem todos os que usam trabalho familiar são agricultores familiares. Segundo essa autora há várias diferenças, claramente definidas, entre agricultor familiar e camponês.

A primeira, segunda e terceira dessas diferenças se complementam e são autoexplicativas.

Quadro 2. Diferenças entre a categoria de camponês e de agricultor familiar

\begin{tabular}{|l|l|}
\hline \multicolumn{1}{|c|}{ Camponês } & \multicolumn{1}{c|}{ Agricultor familiar } \\
\hline 1. Vende só o excedente & Vende tudo o que produz \\
\hline 2 Produz para autoconsumo & Abastece-se nos mercados locais \\
\hline 3. Não segue sinais de preços & Muda de produto em função dos preços \\
\hline 4. Baixa mobilidade de fatores: terra comunal & Alta mobilidade dos fatores: propriedade privada da terra \\
\hline 5. Integração parcial em mercados incompletos: crédito na folha & Integração em mercados completos: crédito com juros de mercado \\
\hline 6. Relações pessoais: submissão, clientelismo, paternalismo & Relações objetivas com os agentes de mercado \\
\hline 7. Resíduo de épocas feudais & Fenômeno século XX, após leis agrícolas \\
\hline 8. Não lutam por melhores condições & Organizam-se por juros, preços, tributos \\
\hline 9. Política agrária, educacional, saúde, infraestrutura. & Política agrícola stricto sensu \\
\hline
\end{tabular}

Fonte: Ellis (1988), Friedmann (1980) e Gasson et al. (1988). 
Os agricultores familiares respondem aos sinais de preços de mercado e têm flexibilidade e adaptação, enquanto que os camponeses vendem apenas o excedente e têm padrões rígidos de produção, ou seja, não mudam de produto em função de alterações de preços de mercado.

A quarta também é simples de entender: os camponeses costumam manter áreas de trabalho comunitário, como no Nordeste em torno dos açudes, os faxinais de antigamente no Paraná, as florestas para extração seringueira ou de babaçu na região amazônica, etc. Quando o desenvolvimento econômico atinge essas regiões, a terra normalmente deixa de ser comunitária e passa a se integrar nos mercados de fatores, sobretudo para poder servir de colateral nos créditos rurais. Terra comunitária é sinônimo de agricultura camponesa e tende a desaparecer inexoravelmente à medida que os mercados se expandem.

Nas regiões camponesas vigoram mercados incompletos ou imperfeitos, tais como o crédito na folha, que implicam juros de até $100 \%$ ao ano, e formas de intermediação extorsivas de tipo mercantil (atravessadores). Em áreas de agricultura familiar os mercados são completos e mais perfeitos: os agricultores familiares tomam crédito a juros normais de mercado e vendem seus produtos em condições também normais, através de intermediários, traders ou cooperativas, e não de atravessadores.

A sexta se refere a uma questão antropológica fundamental, que trata das relações de trabalho: quanto mais desenvolvido é o mercado capitalista, mais objetivas - por meio de contratos - tendem a ser as relações entre trabalhadores e empregadores. Termina assim a fase do clientelismo, paternalismo e abusos típicos do coronelismo semifeudal que existia em muitas partes do Brasil até tempos recentes e que ainda subsiste em algumas áreas do Nordeste brasileiro. $\mathrm{O}$ agricultor familiar, diferente do camponês, procura estabelecer relações contratuais, que podem defendê-lo dos abusos e oportunismo vindos dos agentes das cadeias agroindustriais.

Fica evidente pela questão anterior que a categoria "camponês" é um resquício de épocas semifeudais, enquanto que o agricultor familiar é um produto novo, criado à luz das reformas agrárias do século XX (Japão, Coreia do Sul, Taiwan, Itália, Chile) e das leis agrícolas (Farm Bill) e CAP na Europa, que apoiaram e ajudaram esse setor a se integrar positivamente nos mercados modernos. Na verdade, houve um fracionamento no seio dos camponeses, uns viraram agricultores familiares modernos, e outros, ou migraram ou conseguiram subsistir como agricultores familiares pobres (classes C e D em nossos cálculos) em função do autoconsumo, aproveitam a moradia gratuita e/ou desenvolvem algum artesanato ou empregos fora do estabelecimento, como acontece no Brasil em muitas regiões.

Mas também houve crescimento autêntico da categoria dos agricultores familiares, com integração de pessoas oriundas de classes médias urbanas que passaram a visualizar o agronegócio familiar como algo interessante e rentável. Este fenômeno é bastante generalizado em áreas que foram antes de reforma agrária, por exemplo, no Chile e que se transformaram em estruturas produtivas com dinâmica empresarial, porém, geridas por famílias e membros das famílias dos proprietários. Também se verifica este fenômeno em perímetros irrigados do Nordeste brasileiro, em torno de alguns açudes, principalmente em Petrolina/Juazeiro, nos perímetros da Companhia de Desenvolvimento dos Vales do São Francisco e do Parnaíba (Codevasf).

Finalmente, cabe destacar as diferenças que ocorrem na relação destas categorias com os agentes de mercado e com o Governo. Os camponeses tendem a ser fatalistas, e aceitam submissamente as condições impostas pelos proprietários, que muitas vezes cedem terras a eles em troca de favores pessoais e econômicos. A luta pela terra é talvez a única fonte de conflito sério que se verifica entre os camponeses e os proprietários.

Já os agricultores familiares, segundo Friedmann (1980), estão atentos às mudanças de políticas agrícolas e se mobilizam de forma frequente para lutar por juros menores nos financiamentos, por preços mínimos que remunerem sua atividade, por taxa de câmbio melhor para as exportações e por menores tributos. 
As motivações e a racionalidade diferenciada destas duas categorias (agricultores familiares e camponeses) sugerem que políticas diferenciadas devem ser pensadas para cada um desses segmentos. Políticas agrárias devem ser voltadas preferencialmente para os agricultores pobres, como os chamados camponeses, que não têm todos seus fatores de produção em linha e em condições para se integrar aos mercados: falta-lhes terra (muitos são minifundistas), falta-lhes infraestrutura (não têm estábulos, galpões, cercas, maquinários), falta-lhes educação básica para entender, por exemplo, as bulas dos defensivos, faltam-lhes saúde física para poder trabalhar, faltam-lhes calorias para desenvolver as atividades com energia suficiente. Em suma, sem fortalecer previamente esses aspectos estruturais não adianta dar-lhes crédito de custeio subsidiado ou preços mínimos porque eles vão inexoravelmente destinar esses apoios para cobrir necessidades insatisfeitas no passado em termos de consumo de alimentos, ou de pagamento de dívidas, destinando pouco ou quase nada aos aspectos produtivos de curto prazo, que era o objetivo desse tipo de financiamento. Esses agricultores devem ser atendidos principalmente com políticas agrárias e sociais e não com políticas agrícolas stricto sensu.

Já os agricultores familiares do tipo descrito na primeira parte deste artigo podem e devem ser objeto de atendimento com políticas agrícolas porque eles respondem positivamente aos sinais de mercado e, portanto, serão capazes de aproveitar essa política em benefício da produção e produtividade agrícolas. Crédito de custeio, crédito de investimento, apoio à comercialização, transferência de tecnologia, cooperativismo, seguro agrícola, são todas políticas possíveis de serem implementadas junto a este setor.

\section{7. À Guisa de conclusão}

A primeira constatação que foi possível fazer neste texto responde positivamente à pergunta do título. Existe sim no Brasil um setor que comparte as características do "familiy farming" ame- ricano. Conforme foi mostrado no Quadro 1, os Censos Agropecuários do IBGE, trabalhados com base na metodologia FAO/Incra, revelaram o perfil deste segmento, que está composto por aproximadamente 450 mil produtores agrícolas, que geram em torno de $25 \%$ do PIB agrícola do País, auferem uma renda média líquida de $\mathrm{R} \$ 53.000$ por ano, são especializados e controlam área média de aproximadamente 50 hectares. Há um setor que se segue ao anterior, que é o grupo B da categorização, que aufere renda média de apenas $\mathrm{R} \$ 3.500$ por ano, o que o exclui da possibilidade de realizar investimentos e progredir em sua integração aos mercados.

A segunda constatação, que se deduz da anterior, diz respeito à afirmação do artigo chamado "sete teses" (BUAINAIN et al., 2013) de que no Brasil existe uma agricultura "bifronte", com um setor produtivo composto de 30 mil produtores e um resto de pobres rurais marginalizado e difuso. Está provado que, além dos 30 mil superprodutivos, existe no Brasil um segmento completamente ignorado pelos autores das sete teses, que é o segmento dos agricultores familiares modernos, cuja produção soma também aos $50 \%$ dos 30 mil, acrescentando outros $25 \%$ a mais do PIB agrícola, perfazendo juntos pelo menos $75 \%$ do PIB agrícola brasileiro.

Quem produz os restantes 25\%? São os mais de três milhões de produtores dos grupos $\mathrm{B}, \mathrm{C}$ e $\mathrm{D}$ da análise feita com base na metodologia $\mathrm{FAO} /$ Incra.

A heterogeneidade da agricultura brasileira tem o seguinte perfil: a) um segmento altamente produtivo e eficiente, de tipo patronal empresarial; b) um segmento também eficiente e rentável, de tipo familiar empresarial e c) um segmento de agricultores familiares pobres ou camponeses que produz para autoconsumo, mora no estabelecimento, gera emprego para os filhos, e que não migra porque seu custo de oportunidade para migrar é baixo, conforme se mostrou anteriormente.

A inexistência de economias de escala constantes na agricultura, a baixa lucratividade de atividade em função da baixa rotatividade do 
capital fixo, o ambiente concorrencial do mercado agrícola e os riscos que atingem a atividade em função de clima, pragas e preços, fazem com que não haja interesse em monopolizá-lo por um setor único de produtores, o que abre espaço, portanto, para a coexistência entre setores heterogêneos do meio rural, cada um com sua própria lógica e seus próprios interesses e reivindicações.

Surge nesse sentido outra discordância com as sete teses: nesse artigo se propõe criar um "escudo protetor" para os mais de três milhões de produtores marginalizados e pobres. Que tipo de escudo protetor? $\mathrm{O}$ artigo não se pronuncia, deixa vaga a resposta e sujeita a especulações. Seria uma barreira como a que separa México dos EEUU? Obviamente que essa não pode ser uma resposta adequada. Na verdade, o artigo e posições anteriores de Alves e Rocha (2010) revelam que se está sugerindo um grande "bolsa família" para esse segmento, que pudesse retardar sua completa desaparição ou favelização.

Não acreditam em absoluto na possibilidade de que esse setor possa cumprir alguma função produtiva que lhe permita gerar sua própria renda ao invés de ter que depender do paternalismo estatal.

Embora o aparelho de políticas agrárias criado pelos governos FHC/Lula/Dilma esteja infestado de erros e ineficiências, não há como negar que teve, em boa parte, efeitos positivos junto a esse público. Há exemplos importantes de geração de renda em pequenas agroindústrias familiares (não coletivas) no Nordeste (polpa de frutas, laticínios, mandioca, apicultura), de avicultura no Sul, de processamento de frutas tropicais na região Amazônica, de comercialização com bons resultados através do PAA e do PNAE, de crédito fundiário com a correspondente quitação das dívidas em várias regiões do País, de crescimento da produção graças ao Pronaf etc.

Ao invés de jogar fora tudo o que foi feito nas últimas décadas, acreditamos que é mais adequado propor seu aperfeiçoamento nos casos em que possa ser feito e, eventualmente, a substituição de algumas políticas por outras melhores.
A principal sugestão é, nesse sentido, que se trate com políticas diferenciadas o público diferenciado que compõe o setor da agricultura familiar no Brasil.

1. Reduzir o escopo das políticas agrícolas (Pronaf custeio, tecnologia, preços) para atender principalmente os setores do grupo A, e eventualmente parte do grupo B.

2. Desenvolver e aplicar políticas agrárias estruturantes para os grupos B, C e D do tipo: acesso à terra via crédito fundiário, infraestrutura, saúde, educação, assistência técnica.

3. Ao invés de dirigir o crédito do Pronaf a categorias de renda ou de idade, dirigi-lo a cadeias agroindustriais específicas (que devem ser priorizadas) procurando aprimorar a integração do agricultor familiar no agronegócio.

4. Aumentar a participação do crédito de infraestrutura dentro dos financiamentos do Pronaf, diminuindo a parcela de custeio.

5. Eliminar os rebates nos reembolsos dos créditos: o rebate é deseducativo e não ajuda na conversão dos agricultores em tomadores e clientes do sistema de crédito.

6. Repensar e redimensionar o programa de territórios, que pode estar distribuindo recursos de forma difusa e com superposição com outras linhas de crédito.

7. Realizar uma ampla avaliação do impacto real que o Pronaf e os programas complementares tiveram junto ao seu público-alvo. Essa avaliação pode ser realizada com apoio das Universidades Federais e Estaduais e centros de pesquisa especializados.

Em suma, algumas políticas podem e devem ser mantidas e outras podem ser reformuladas, mas o Brasil, pelo tamanho e pela heterogeneidade de sua estrutura agrária, não pode depender de um tipo único de produtor nem de uma 
única política agrícola. Deve necessariamente diversificar seu público e adequar suas políticas para atender os diversos segmentos da melhor forma possível.

\section{Referências bibliográficas}

ALVES, E. e ROCHA, D. P. Ganhar tempo é possível? In: GASQUES, VIEIRA FILHO e NAVARRO (Orgs.). A agricultura Brasileira: desempenho, desafios, perspectivas. Brasília: IPEA, 2010.

BERRY, A. e CLINE, W. Agrarian structure and productivity in developing countries. Baltimore: Johns Hopkins University Press, 1979.

BINSWANGER, H. Quais são as Perspectivas para a Reforma Agrária? Pesquisa e Planejamento Econômico. IPEA, v. 19, n. 1, abr. 1989.

BUAINAIN, A., ALVES, E., SILVEIRA, J.M. e NAVARRO, A. Sete Teses sobre o mundo rural brasileiro. Política Agrícola, ano XXII, n. 2, abr.jun. 2013.

BUTTEL, F. e LaRAMEE, P. The disappearing middle, a sociological perspective, Towards a New Political Economy of Agriculture. Firedland, W., Boulder: Westview Press, 1991.

ELLIS, F. Peasant Economics: Farm Households In Agrarian Development Published April 10th 2003 by Cambridge University Press (first published March 25th 1988).

FRIEDMANN, H. Household Production and the National Economy. The Journal of Peasant Studies, v. 7, n. 2, p. $158-184,1980$.

GASSON, R. et al. The farm as a family business: a review. Journal of Agricultural Economics, Oxford, v. 39, n. 1, p. 1-43, jan. 1988.
GUANZIROLI, C. E., BUAINAIN, A. M. e DI SABBATO, A. Dez anos de evolução da agricultura familiar no Brasil: (1996 e 2006). RESR, v. 50, n. 2, 2012.

KRAUSE, K. L. Large-Size farms in the United States. Agricultural Economics, p. 1-35, jan. 1988.

LEWIS, W. A. O desenvolvimento econômico com oferta ilimitada de mão-de-obra (1954). In: AGARWALA, A.N. e SINGH, S. P. (Orgs.). A economia do subdesenvolvimento. Rio de Janeiro: Forense, 1969.

LUND, P. J. e HILL, P. G. Farm Size, Efficiency and Economies of Size. Journal of Agricultural Economics, v. 30, n. 2, mai. 1979.

MANN, S. e DICKINSON, J. Obstacles to the development of a capitalist agriculture. The Journal of Peasant Studies, London, v. 5, n. 4, p. 466-481, jul. 1978.

MAPA. Ministério de Agricultura, Pecuária e Abastecimento. Site acessado no dia 25/06/2014.

STANTON, B.F . Perspective on Farm Size. Journal of Agricultural Economics, p. 727-737, dez. 1978.

USDA. Censos Agropecuários Estados Unidos 1999 e 2007.

. Economic Research Service and National Agricultural Statistics Service, 2012 Agricultural Resource Management Survey.

VAN DER PLOEG, J. D. Sete teses sobre a agricultura camponesa. In: Agricultura familiar camponesa na construção do futuro, Rio de Janeiro: ASPTA, 2009.

VEIGA, J. E. O Desenvolvimento Agrícola, uma visão Histórica. São Paulo: Hucitec, USP, 1991.

VERGOPOULOS, K. Capitalism and peasant productivity. The Journal of Peasant Studies. London, v. 5, n. 4, p. 446-465, jul. 1978. 
